\title{
Modeling and Simulation of Energy Management Hybrid Sources System composed of Solar-PV and Battery
}

\author{
M. Maamir ${ }^{1}$, A.Betka ${ }^{1}$, H. Aboub $^{2}$ \\ ${ }^{1}$ LGEB Laboratory, Electrical Engineering Department, University of Biskra, Algeria, \\ ${ }^{2}$ LEB, university of Batna \\ Email:m.maamir39@gmail.com
}

\begin{abstract}
This paper describes the modeling and control of a hybrid source consisting of PV generator (as main source) along with a battery (as an auxiliary source) and a dc-load are connected through power converters and a dc-link. The main objective of this paper is to design a power manager to control effectively the power of the different sources. To test the effectiveness of the different control techniques involved, simulation results are plotted and commented.
\end{abstract}

Keywords: Hybrid system, energy storage, PV generator, Power management, battery, fuzzy logic, batteries.

\section{INTRODUCTION}

Currently, most of the energy demand in the world is met by fossil and nuclear power plants. A small part is drawn from renewable energy technologies such as wind, solar, fuel cell, biomass and geothermal energy [1]. Renewable energy sources are considered as alternative energy sources to conventional fossil fuel energy sources due to the environmental pollution and global warming problems. The combination of all different kinds of available renewable energy associated with available energy storage units produces an hybrid energy system (HES) [2]. Therefore, in order to supply electric power to fluctuating loads with a hybrid system composed of solar cell and electric energy-storage system is needed to compensate for the gap between the output from the renewable energy sources and the load, in addition to the collaborative load sharing among those energies.

To control the power flow among the elements Consisting HES a suitable energy management system (EMS) must be designed. The EMS is usually a central controller that drives all the elements. Thus, the complexity in designing an EMS increases with the level of hybridization of the HES (the number of elements present in the system).

Energy management of multi-power sources has already been studied recently, for example, Control, robustness, stability, efficiency, and optimization of hybrid sources remain an essential area of research. Several researchers have studied different topologies. G. Boukettaya [3] studied A dynamic power management strategy of a grid connected hybrid generation system using wind, photovoltaic and Flywheel Energy Storage System in residential applications. R. Souad [4] studied the development and the realization of an Intelligent Power Strip for Energy Consumption Management in Hybrid Wind/Photovoltaic Systems. M. Mohammedi [5], studied Passivity Based Control and Fuzzy Logic Estimation applied to DC Hybrid Power Source using Fuel Cell and Super capacitor. Shiyas P.R [6] Fuzzy controlled Dual input DC/DC Converter for Solar-PV/Wind Hybrid Energy System. M. Y. Ayad [7], studied Sliding Mode Control applied to Fuel Cell, Super capacitors and batteries for Vehicle Hybridizations.

In this paper, a control strategy for the energy management of an hybrid renewable energy system is presented. The system is composed of a photovoltaic solar array and batteries which are connected in a common dc-link bus. The DC bus is connected in parallel with resistive charge. DC-DC power converters are introduced to quietly perform the different control strategies proposed. Fig. 1 is shown a synoptic scheme of the system. The paper focuses on the design of a power supervisor able to decide, at each moment and according to the load power demand, which source has to supply or absorb the energy and eventually define the ratio of using of different sources in the same time [8]. The rest of the paper is organized as follows: In section2; an explicit 
modeling of the different sub-systems are given. In section3, both the power management algorithm and the proposed control techniques are properly detailed. In section 4 , simulation results conducted with both various load demand.

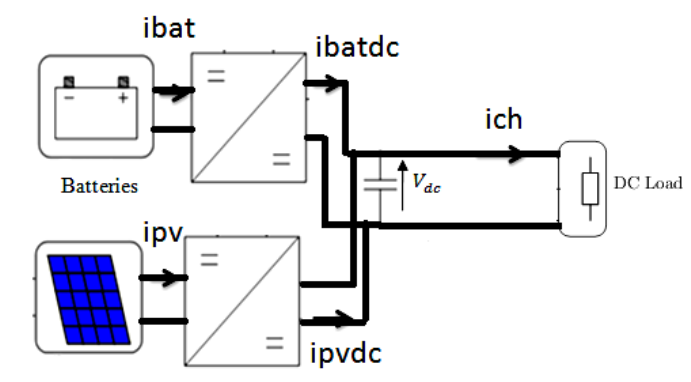

PV generator

Fig1: System architecture

\section{SYSTEM MODELING}

\subsection{PV Array Model}

The equivalent circuit of the PV device can be represented as a current source in parallel with diode includes a parallel resistor (Rsh) expressing a leakage current, and a series resistor (Rs) describing an internal resistance [9]. The model is shown in Fig2.

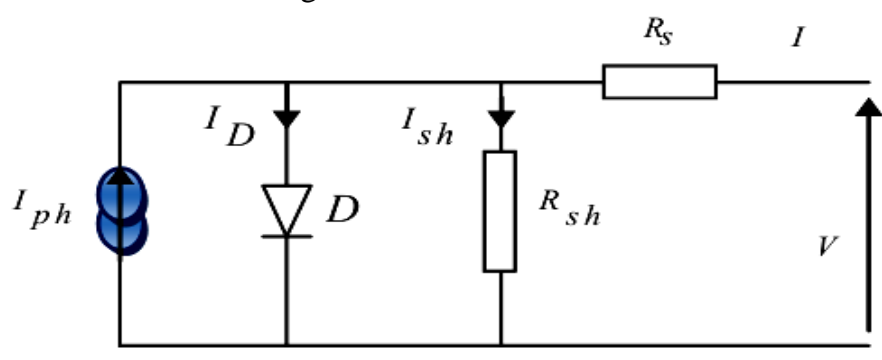

Fig 2: equivalent circuit of Photovoltaic module.

Since Rsh is very high, the mathematical model which relates the output current to the output voltage is given by the following expression [10]:

$$
\mathrm{I}=\mathrm{I}_{\mathrm{cc}}-\mathrm{I}_{0}\left[\exp \left(\frac{\mathrm{V}+\mathrm{R}_{\mathrm{p}} \mathrm{I}}{\mathrm{V}_{\mathrm{th}}}\right)-1\right]
$$

The adaption of Eq. (1) for different levels of solar insolation and temperature can be handled by the following equations.

$$
\begin{gathered}
\Delta T=T-\mathrm{T}_{\text {ref }} \\
\Delta \mathrm{I}=\alpha\left(\frac{\mathrm{E}}{\mathrm{E}_{\text {ref }}}\right) \Delta \mathrm{T}+\left(\frac{\mathrm{E}}{\mathrm{E}_{\text {ref }}}-1\right) \mathrm{I}_{\text {ccref }} \\
\Delta \mathrm{V}=-\beta \Delta \mathrm{T}-\mathrm{r}_{\mathrm{s}} \Delta \mathrm{I} \\
V=V_{\text {ref }}+\Delta \mathrm{V} \\
\mathrm{I}=\mathrm{I}_{\text {ref }}+\Delta \mathrm{I}
\end{gathered}
$$

\subsection{Battery model:}

In general a battery device can be viewed as a voltage source $E_{b a t}$ in series with an internal resistance $r_{b a t}$ as shown in fig 3. [8]. 


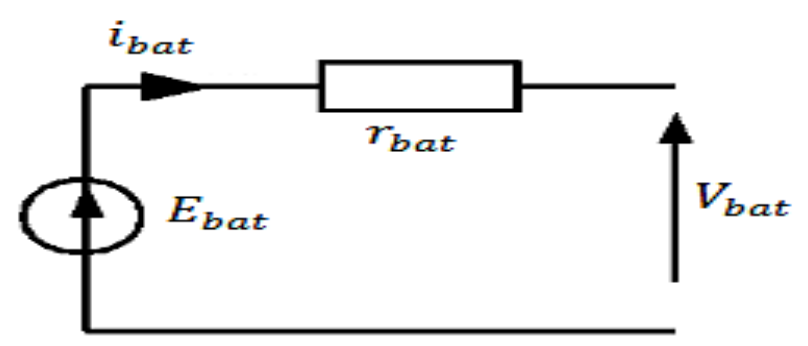

Fig 3: Dynamic model of lead-acid battery

The terminal voltage $V_{b a t}$ is given by:

$$
V_{b a t}=E_{b a t}-r_{b a t} \cdot i_{b a t}
$$

As the internal voltage $E_{b a t}$ is assumed to be a function only of the state of charge (SOC) [11] [12], or the depth of discharge $\left(D O D_{b a t}\right)$. Eq. (8) describes the used open voltage:

$$
E_{\text {bat }}=n\left(2.15-D O D_{b a t} \cdot(2.15-2.00)\right.
$$

In addition, $\mathrm{SOC}_{\mathrm{bat}}$ and $D O D_{\text {bat }}$ are respectively estimated by [11]:

$$
\begin{gathered}
S O C_{\text {bat }}=\frac{C_{\text {actuelle }}}{C_{\text {totale }}}=S O C_{b_{\text {int }}}+\frac{100}{C_{N}} \int i(t) d t \\
\text { DOD bat }=1-S O C_{\text {bat }}
\end{gathered}
$$

\subsection{Average state-space models of the static converters}

\section{- $\quad$ DC/DC boost converter model:}

The dc-dc boost is modeled using an average state-space approach, given in eq (11) [12] to check the effectiveness of the control techniques via continuous models:

$$
\left[\begin{array}{c}
\frac{d i_{L}}{d t} \\
\frac{d v_{c}}{d t}
\end{array}\right]=\left[\begin{array}{cc}
0 & -\frac{1-\alpha_{p v}}{L_{p v}} \\
\frac{1-\alpha_{p v}}{C} & -\frac{1}{R C}
\end{array}\right]\left[\begin{array}{c}
i_{L p v} \\
V_{c}
\end{array}\right]
$$

In order to maximize the energy extracted from the PV array, a fuzzy logic based MPPT strategy has been applied because it has the advantages of robustness, and minimal requirement for accurate mathematical model [13].

\section{- Bidirectional DC/DC converter model}

The bidirectional DC/DC converter is a current reversible DC/DC converter. It can work as a boost converter when the current (of the bidirectional DC/DC converter inductance) flows from the super capacitor (battery) to the DC bus. It works as buck converter when the current flows on the opposite direction [14]. Thus, to achieve energy transfer in two directions, the buck and boost converters were associated as shown in Fig 4.

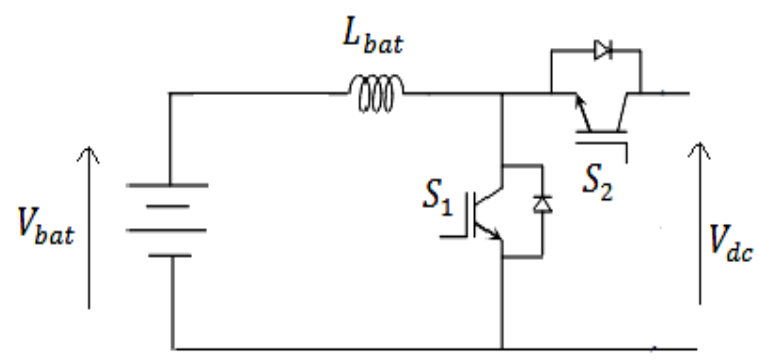


Fig 4: Structure of the bidirectional DC-DC converter

The average model of the converter in both power direction flow can be written as:

$$
\mathrm{L}_{\mathrm{bat}} \frac{\mathrm{di}_{\mathrm{bat}}}{\mathrm{dt}}=\mathrm{V}_{\mathrm{bat}}-\left(1-\alpha_{\mathrm{bat}}\right) \mathrm{V}_{\mathrm{dc}}
$$

\section{CONTROLLER FOR HYBRID SYSTEMS}

In the present work, three operating modes are distinguished and smoothly permuted through the presented power management system. Throughout the simulation the photovoltaic generator operates on MPPT:

- Mode1: the main source is the PV array and the battery, supply energy to the load.

- Mode2: power load is below to the maximum power point (MPPT), then the battery is charged.

- Mode3: This mode starts when the power of the PV array demand equal to the power demand, where the Photovoltaic array supplies only the load demand.

To permit a global flow of the different source's energy, the DC bus must be kept constant. A main voltage loop with a Lyapounov controller generates the total current reference that should be taken from the dc-link bus. In the EMS depicted in (Fig 5), a low-pass filter is introduced, which extracts the low frequency content of the reference sent to the battery, and through the chosen constant time, the battery contributes mainly in steady state. The rules are summarized in eq. (13) for battery.

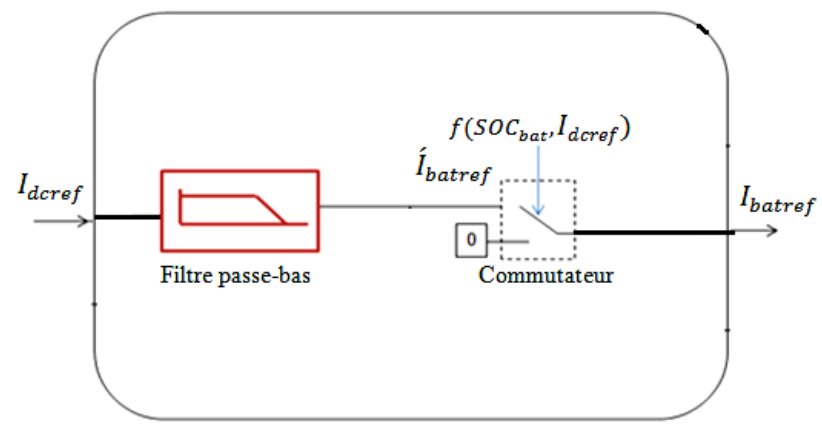

Fig 5: Energy management system

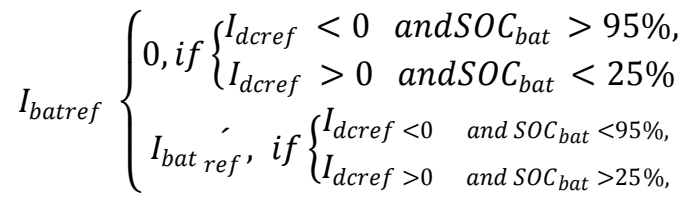

\section{- Battery current control loop}

The design of the bidirectional DC-DC converter of the battery or SC is based on the direct lyapunov theory. The controller adjusts the duty cycle by comparing the reference and the actual battery currents to operate the converter in boost and buck mode [15].

Let the battery current error defined as :

$$
\mathrm{e}=\mathrm{I}_{\text {bat }}-\mathrm{I}_{\text {bat }} \text { ref }
$$

One can define a quadratic positive defined function related to the tracking error [16]:

The gradient function of the loss function $\mathrm{V}$ is derived as:

$$
\mathrm{V}=\frac{1}{2} \mathrm{e}^{2}
$$

$$
\dot{\mathrm{V}}=\dot{\mathrm{e} e}
$$

To ensure the error convergence to zero, Let's choose the desired gradient function of the form:

$$
\dot{\mathrm{V}}=-\mathrm{Ke}^{2}
$$

By a proper adjustment of the constant $\mathrm{K}$, the system dynamics are improved, and the battery current tracks its reference in a finite time.

By equation (16) and (17), the closed loop error dynamic is derived as a stable first order equation:

$$
\dot{\mathrm{e}}=-\mathrm{Ke}
$$

The duty cycle is computed as:

$$
\alpha_{b a t}=1-\frac{V_{e}}{V_{d c}}
$$




\section{- PV current control loop}

The PV panels are equipped with the maximum power point tracking controller to track the MPP and extract maximum possible power from the panel [17].

In this study, fuzzy logic has been applied for tracking the MPP of PV systems because it has the advantages of robustness, design simplicity, and minimal requirement for accurate mathematical model [18].

The fuzzy controller consists of three blocks: the fuzzification of input variables which is performed in the first block, it allows the passage from the real domain to fuzzy domain. The second block is devoted to inference rules, while the last block is the defuzzification for returning to the real domain. This last operation uses the center of mass to determine the value of the output. Fig 6 shows the basic structure of the used MPPT Fuzzy controller [18].

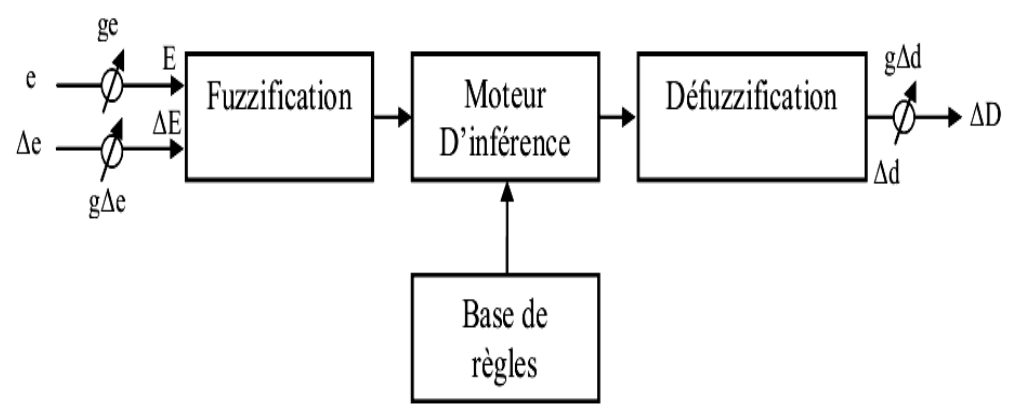

Fig 6: Block diagram of the fuzzy logic controller

\section{SIMULATION RESULTS}

The whole system has been implemented in the Malab-simulink using the system parameters shown in table1.

Table 1: Sources parameters

\begin{tabular}{|l|l|l|l|}
\hline \multicolumn{4}{|c|}{ Photovoltaic generator } \\
\hline Vop $=68.8 \mathrm{v}$ & Iop $=14 . \mathrm{A}$ & $\mathrm{Icc}=15.3 \mathrm{~A}$ & Voc $=86 . \mathrm{v}$ \\
\hline Battery & Vbat $=48 \mathrm{v}$ & $\mathrm{Cn}=200 \mathrm{~h}$ & $\mathrm{n}=24$ cellule \\
\hline
\end{tabular}

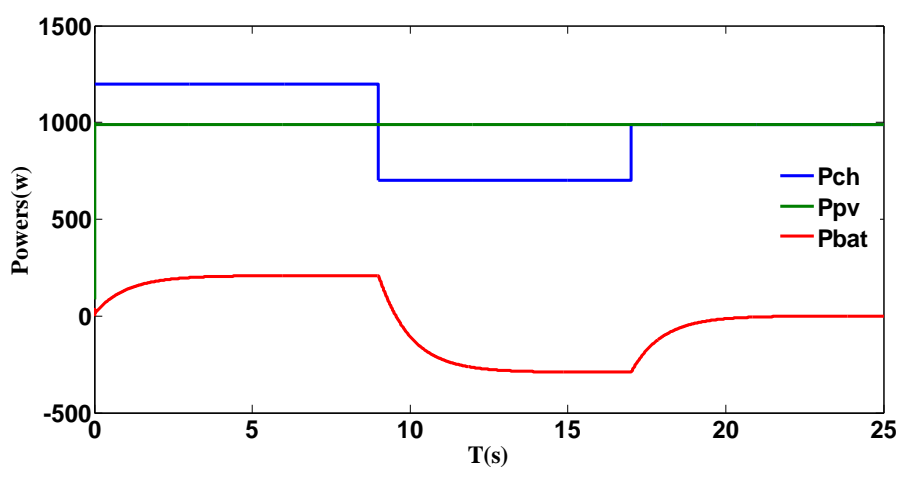

Fig 7 : Load demand and battery Power 
Madiha. Maamir et al

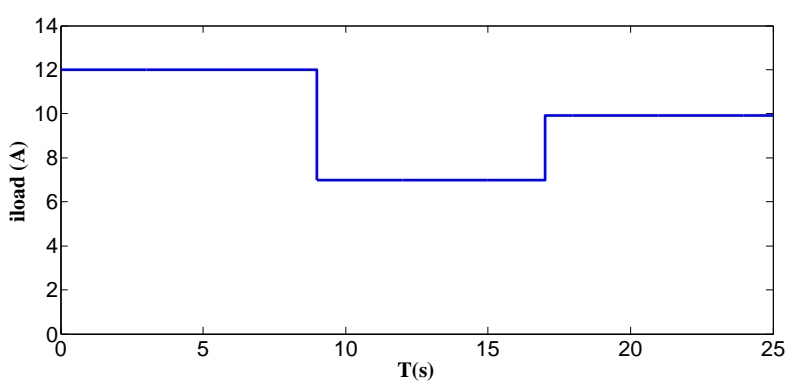

Fig $8:$ Load current

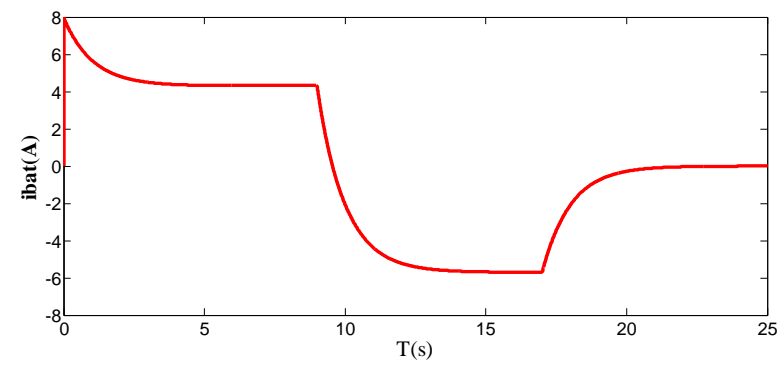

Fig 9 : battery current

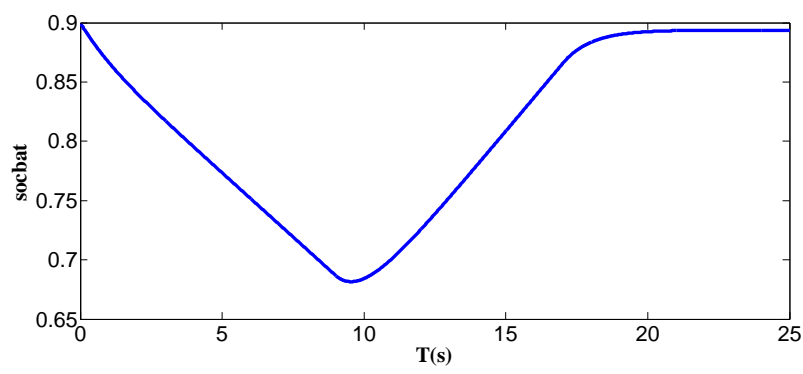

Fig 10: State of charge

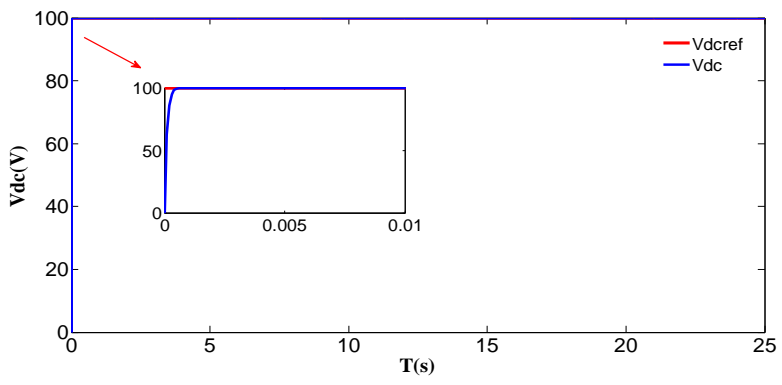

Fig 11: dc-link voltage

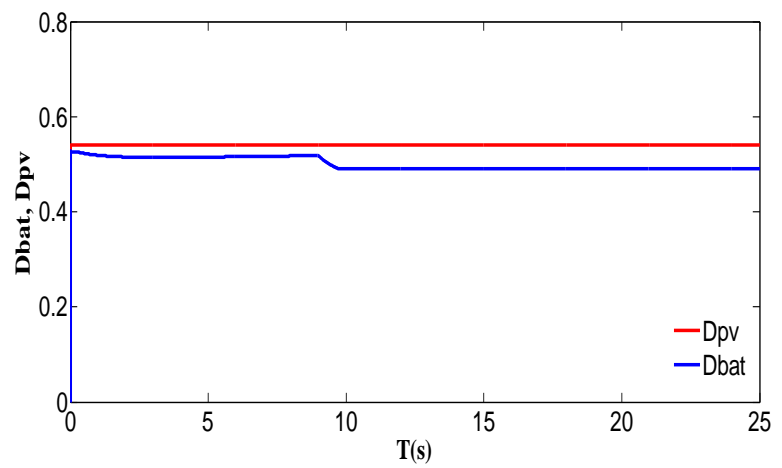

Fig 12: PVG Boost and battery bidirectional converters controls 


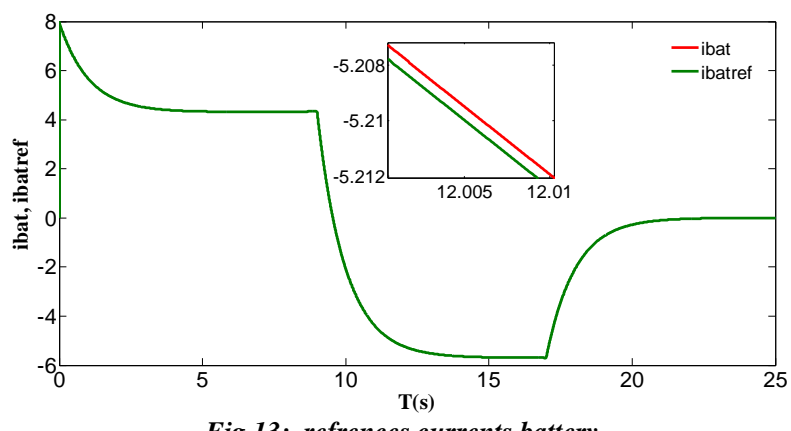

Fig 13: refrences currents battery

Fig 7 shows the powers transfer of the system, the PV generator and the battery provide the power to the load $(0 \mathrm{~s}-9 \mathrm{~s})$.To $9 \mathrm{~s}$ at $17 \mathrm{~s}$, the PV generator suplyies energy to the load and charge the battery, when the power load equals the power of the PV generator the battery current becomes zero (17s-25s).

In fig 10, increase battery state of charge correspond to a charge, and the decrease to a discharge.

The DC bus voltage tracks well the reference without overshoot and no state error (with a response time of $0.00065 \mathrm{~s}$ ) (fig 11).

Fig 12 presents the network boost controller, the the battery bidirectional converter controller. $\alpha_{p v}$ and $\alpha_{b a t}$ are in the interval [0.5].

Fig 13 shows the battery current ibat. It tracks well the reference, this current becomes positive to compensate for an increase in the load power demand that oppears between time ( $\mathrm{t}=0 \mathrm{~s}$ and $\mathrm{t}=9 \mathrm{~s})$ resulting in discharge of the battery, negative when the battery is charged (for example between $t=9 \mathrm{~s}$ and $t=17 \mathrm{~s}$ ) and takes zero values if the battery is completely Charged or discharged.

\section{CONCLUSION}

Energy management of multi-power sources has been proposed as a solution for a hybrid energy system that uses renewable energy from solar cells and a storage with batteries, when the PV array is used as a source of power supply to stand alone loads, it is necessary to use the MPPT to get the maximum power point from the PV array and implemented with MATLAB/SIMULINK for simulation. The Energy management System (EMS) is operated in suitable modes according to the conditions of PV panel and battery.The problem of the DC Bus Voltage control is solved by using a direct lyapunov theory.

\section{EFERENCES}

[01] Phatiphat Thounthong, Viboon Chunkag, Panarit Sethakul, Suwat Sikkabutc, Serge Pierfederici, Bernard Davat, " Energy management of fuel cell/solar cell/supercapacitor hybrid power source”, Journal of Power Sources 196, elsivier, 2011, pp. 313-324.

[02] Gupta, A., R. P. Saini, and M. P. Sharma, "Hybrid Energy System Sizing Incorporating Battery Storage: An Analysis via Simulation Calculation",third International Conference on Power Systems, 2009.

[03] GhadaBoukettaya, Lot fi Krichen, "A dynamic power management strategy of a grid connected hybrid generation system using wind, photovoltaic and Flywheel Energy Storage System in residential applications", journal homepage, Contents lists available at Science Direct, 2014, pp 148 - 159.

[04] RAFA Souad, KHENFRI Fouad, DIAF Said," Development and Realization of an Intelligent Power Strip for Energy Consumption Management in Hybrid Wind/Photovoltaic Systems", The Mediterranean Green Energy Forum 2013, MGEF-13, Science Direct.

[05] M. Mohammedi, M. Becherif, M.Y. Ayad, O. Kraa, A. Aboubou and M. Bahri,” Passivity Based Control and Fuzzy Logic Estimation applied to DC Hybrid Power Source using Fuel Cell and Supercapacitor", Proceedings of the 3rd International Conference on Systems and Control, Algiers, Algeria, October 2931, 2013.

[06] [Shiyas P.R, Kumaravel S. and Dr. Asho S, "Fuzzy controlled Dual input DC/DC Converter for SolarPV/Wind Hybrid Energy System", 2012 IEEE Students.

[07] M. Y. Ayad, M. Becherif, A. Henni, M. Wack and A. Aboubou, "Sliding Mode Control applied to Fuel Cell, Supercapacitors and batteries for Vehicle Hybridizations", IEEE International Energy Conference, 2010. 
[08] H. Alloui, M. Becherif and K. Marouani, "Modelling and Frequency Separation Energy Management of Fuel Cell-Battery Hybrid Sources System for Hybrid Electric Vehicle", 21st Mediterranean Conference on Control \& Automation (MED) Platanias-Chania, Crete, Greece, June 25-28, 2013.

[09] Ionel Laurentiu Albotea Nu, Sergiu Ivanov and Gheorghe Manolea, "Modelling and simulation of a stand-alone photovoltaic system", 8th WSEAS International Conference on POWER SYSTEMS (PS 2008), Santander, Cantabria, Spain, September 23-25, 2008.

[010] Angkee Sripakagorna, Nartnarong Lim wuthigraijiratb, "Experimental assessment of fuel cell/supercapacitor hybrid system for scooters" international journal of hydrogen energy 34, Elsevier, pp. 6036-6044, 2009.

[011] Lagrioui, H.Mahmoudi "Nonlinear adaptive Backstepping Control of Permanent Magnet Synchronous Motor (PMSM)" JATIT-Vol 29. No. 2 - 2011.

[012] Premananda Pany, R. K. Singh, R.K.Tripathi, "Performance Analysis of Fuel Cell and Battery fed PMSM Drive for Electric vehicle Application", 2nd International Conference on Power, Control and Embedded Systems, 2012.

[013] H. Afghoul and F. Krim, "Intelligent energy management in a photovoltaic installation using neuro-fuzzy technique", 2nd IEEE ENERGYCON Conference \& Exhibition, 2012.

[014] Mustapha Amine RAHMANI ,Mazen ALAMIR andDavidGUALINO,"Control Strategy For An Off Grid Hybrid Stirling Engine/Super capacitor Power Generation System "American Control Conference (ACC) Washington, DC, USA, June 17-19, 2013.

[015] Premananda Pany, R. K. Singh, R.K.Tripathi, "Performance Analysis of Fuel Cell and Battery fed PMSM Drive for Electric vehicle Application", 2nd International Conference on Power, Control and Embedded Systems, 2012.

[016] Drid. S, A. Makouf, Nait-Said M.S, and Tadjine. M, "The Doubly Fed Induction Generator Robust Vector Control Based on Lyapunov Method", Transactions on Systems, Signals \& Devices Vol. 4, No. 2, pp. 1-13, 1861-5252/ c 2009 TSSD.

[017] Muhammad Sheraz, Mohammed A. Abido, "An Efficient MPPT controller Using Differential Evolution and Neural Network", International Conference on Power and Energy (PECon), 2-5 December 2012.

[018] H. Afghoul and F. Krim, "Intelligent energy management in a photovoltaic installation using neuro-fuzzy technique", 2nd IEEE ENERGYCON Conference \& Exhibition, 2012 